\title{
Power Quality Improvement Using Dynamic Voltage Restorer on Grid-Connected Wind Energy System
}

\author{
M. Praful Yadav*, P. Sujatha, P.B. Kumar \\ JNTUA College of Engineering, Anantapuramu 515002, Andhra Pradesh, India
}

Corresponding Author Email: praful.jntua@gmail.com

https://doi.org/10.18280/ejee.230506

Received: 30 September 2021

Accepted: 18 October 2021

\section{Keywords: \\ renewable energy balanced faults, transient stability, dynamic voltage restorer (DVR), wind generator, power quality, space vector pulse with modulation}

\begin{abstract}
Reduction of fossil fuels and increasing technology made importance of wind generation as renewable energy sources. With increasing number of wind farms fed to grid increases grid fault issues due to various wind systems disconnected from grid during grid faults. To get better grid operation, wind farms are probable to be carried during disturbance related to grid faults extensively known as fault ride through capability. In proposed system a fault ride through method in wind farm management system connected to grid is investigated in term of critical clearing time. This paper examines the use of dynamic voltage restorer on the enhancement of fixed-speed wind generator systems. The controller capability performance, drive performance, and cost factor are considered. Simulation is performed using MATLAB Simulink for constant speed wind generators with closed-loop controllerbased DVR are tested. The constant speed drive called synchronous generator-based wind system feed to an infinite bus system. Simulation results show the wind system with DVR has better fault ride-through capability other compensated voltages and is more efficient in minimizing voltage fluctuations called sag/swell and wind generator's speed. Additionally, DVR aids wind generators to maintain voltage sag/swell with the grid limits requirements with economical as compared to other voltage compensating systems.
\end{abstract}

\section{INTRODUCTION}

Due to the increase in requirement of electric energy and decrease of energy production resources tends to introduction of non convention source energy in power industries. Among various non convention sources of energy source, wind power generation plays a key role due to its freely availability. Wind power generation is drastically upward with percentile of increase of $20 \%$ annually. It is expected by 2025 it might take $15 \%$ of world supplied by wind power generation [1]. Due to the rotational device in the wind system connected to electrical grid possibility of integrations challenges are high. Under grid fault conditions wind turbine gets isolated from grid due to its protection designed and reduces risk of damage.

If wind turbines go on isolated during grid faults the electric network gets mismatch between supply and grid demand. In order to reduce instability problems in wind system connected to grid for existing wind farms as well as new wind project it is necessary to develop system which can overcome disturbances created externally when wind turbines connected to grid. The external faults in the wind system are measure through fault ride through capability of electrical network with wind power. In the proposed system FRT is used to measure the critical clearing time (CCT). During fault occurrences in electrical network with wind power connected to grid may results in generator speed increases beyond its rated value. To avoid damage of the generator rotor a brake procedure is designed which trips the turbine due to overspeed fault in the wind turbine to maintain CCT within threshold limits. The time elapses among the incidence of fault and fault clearing are called critical clearing time. CCT of electrical network connected to wind power generation can be estimated based on approximation steady state system.

The steady state approximation method of wind system connected grid may not give accurate results as compared to transient behavior of the system. FRT capability of wind generator is the ability to reduce disturbance taking place in electric network when associated with gird. FRT helps the network in two ways i.e., one it maximizes amount of power generated can be injected into system with an approach that compensates the external fault effectively. On the other-side FRT can sustain sum of time where generator can preserve with grid during external fault condition. The second method of controlling or ride through the fault is extensively know as critical clearing time techniques of clearing the fault. In CCT method intended values are based on the approximation steady state model of wind system which is demonstrated in brief in next section [2].

There are various compensating devices that are identified to support the ride-through capabilities of wind generators, these devices may be categorized in series compensating and shunt compensating devices based on the design of the auxiliary device connected. A comparison among different shunt devices connected to wind turbine fixed constant speed wind generators called static compensator (STATCOM) is described in DVR and fault current limiters are most extensively used devices as series compensated devices which are connected in series to solve short circuit and voltage variable problems in the wind turbine generator $[3,4]$.

The number of comparative studies of different series devices on the use of wind energy systems has performed better so far. With this background a comprehensive analysis 
of DVR to fulfill the gaps of current limiter on wind systems. Though variable speed wind generators called double fed induction machines and synchronous machines are commonly used in recovering the voltage disturbances due to the use of high power frequency power electronics devices [5]. However, over the last three decades, most of the wind turbines are installed with generators that wind at a fixed speed, so in the report, generators are studied where the most frequent issue of these wind generators are high reactive power consumption during faults \&voltage variation during operation mode results into wind turbine service time out and delay the grid voltage restorations $[6,7]$.

The series device can inject the voltage can compensate the reactive power, also very much know as reactive power compensating device in both cases like wind generators and grid operations. Compared to STATCOM, DVR uses less reactive power and is better at stabilizing issues with fixedspeed wind machines, the shunt compensation devices recover the system less than $1 \mathrm{sec}$ and also reduce the losses to some extent during the operation period $[8,9]$. The simulation model is designed using MATLAB-Simulink.

The efficiency of the suggested system is validated using temporary fault analysis in the Wind Energy feeding to the grid with wind generator \& synchronous generator. Different factors impacting the system in terms of IG terminal voltage variation rotor angle, IG speed deviation, and IG Real power are utilized for assessing the performance of the system. A detailed report on the analysis of DVR on wind systems with faults is demonstrated.

The report of the concept is demonstrated as follows:

$\checkmark$ Modeling of the Wind turbine Management System.

$\checkmark$ Control strategy for Dynamic Voltage Restorer.

$\checkmark$ Outcome of simulation results and Impact DVR on the wind system issues.

$\checkmark$ The conclusion made based on the analysis of validation results.

\section{SYSTEM MODELING WITH WIND TURBINE}

Figure 1 depicts the system model that was developed in Ref. [10]. The system comprises of one "Synchronous Generator" (SG, $100 \mathrm{MVA}$ ), as one wind turbine generator coupled to an infinite bus via a transmission line with series transformer circuits connected DVR with battery system. At the wind Turbine's terminal, DVR is coupled in series.

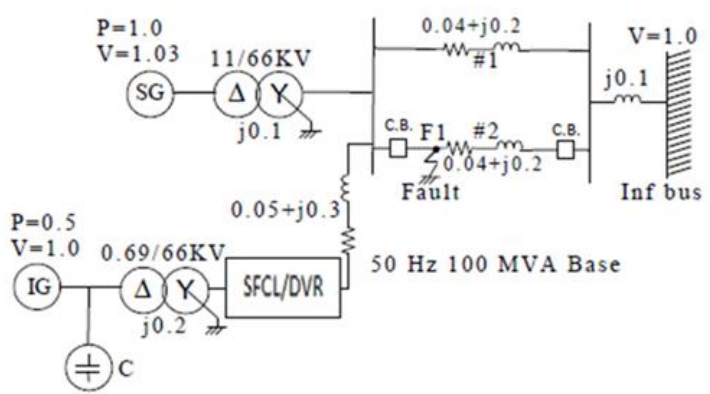

Figure 1. System model with DVR and current limiters

As shown the C.B. (Circuit Breakers) are used at the endpoint of the transmission lines circuit to stop the fault current. A "power factor" (P.F.) of the system is compensated is using compensation capacitor $\mathrm{C}$ is connected to wind generator end voltage terminal to maintain the unity power factor for the IG. The SG parameters used for this concept are utilized from work are developed [11].

$$
\begin{gathered}
\mathrm{P} \omega=0.5^{*} \rho^{*} \pi^{*} \mathrm{R}^{2 *} \mathrm{~V}_{\mathrm{w}}{ }^{3 *} \mathrm{C}_{\mathrm{p}}(\lambda, \beta) \\
\lambda=\frac{\omega_{\tau} R}{V w} \\
\mathrm{Cp}=\frac{1}{}\left(\lambda-0.022 \beta^{2}-5.6\right) \mathrm{e}^{-0.17 h}
\end{gathered}
$$

where,

Pm=Evaluated power from the wind,

$\rho=$ Air density $\mathrm{kg} / \mathrm{m}^{3}$,

$\mathrm{R}=$ Radius of the blade radius in meters,

$\mathrm{Vw}=$ Wind velocity $\mathrm{m} / \mathrm{s}$,

$\mathrm{C} \mathrm{p}=$ Effective coefficient of Power,

$\lambda=$ Tip speed ration,

$\beta=$ pitch angle of the blade in deg,

$\mathrm{Wr}=$ rotational speed in $\mathrm{rad} / \mathrm{sec}$.

Here the tips speed ratio is a function of rotational speed and blade pitch angle. In this concept, the model is considered by Ye et al. [12] for real power characteristics. As a series compensating device, the dynamic voltage restorer maintains a balanced RMS voltage at the wind generating system's terminal under-voltage variation problems like voltage $\mathrm{Sag} / \mathrm{Swell}$ and faults injected into the system via a seriesconnected transformer.

The DVR's fault ride-through capabilities for the synchronous machine are reported in this work. It has many control strategies and designs. An evaluation of several control methods of the DVR is demonstrated by Hasan et al. [13]. A comparative analysis of compensating devices and their Strategy is described in Refs. [14, 15].

The proposed system is shown below with DVR power flow in Figure 2. The energy storage devices connected to the wind generator charge during normal operation and discharge to during fault conditions while reactive \&active power is supplied to the grid and wind generator when voltage recovery is needed.

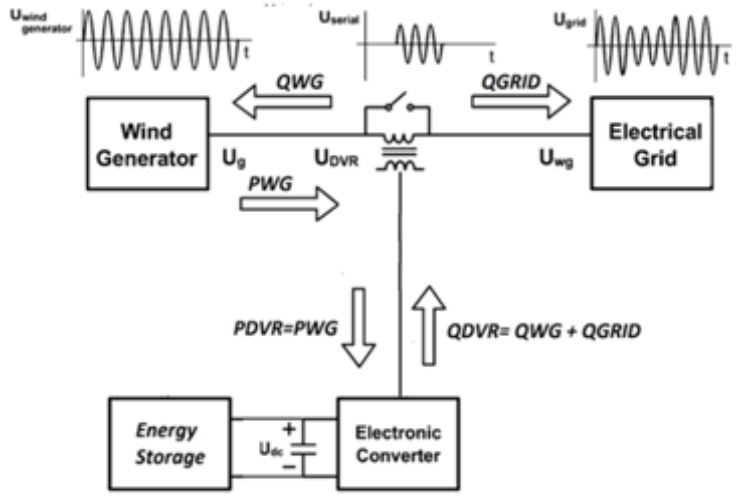

Figure 2. Configuration of DVR

\section{DVR CONNECTION SYSTEM}

A standard test model, including a DVR with various forms of loads, is connected at the PCC ("Point of Common Coupling"), such as a sensitive load, a linear, and a nonlinear 
load. The Series converter connected in series is making DVR with distribution system to achieve through a coupling transformer whose primary is coupled as the interface between load and mains.

However, in the proposed system switching ripple-free DVR voltage is achieved using a passive LC filter circuit as shown in Figure 3. Harmonics canceling characteristics of intelligent controllers aren't included in the analysis of this filter.

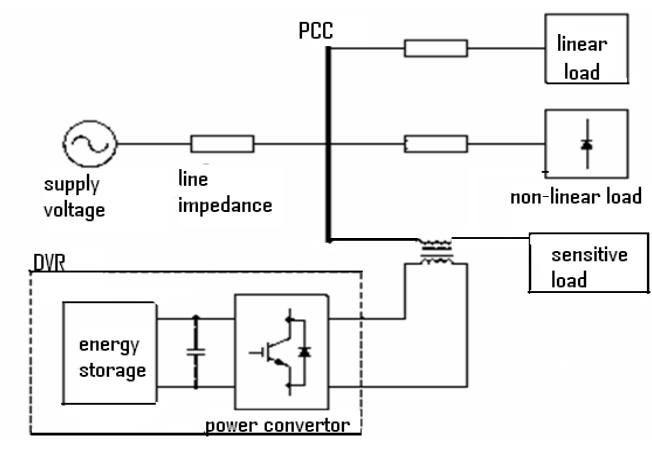

Figure 3. System configuration with DVR

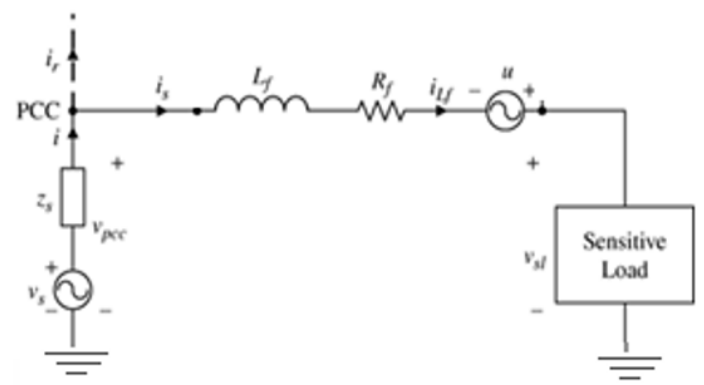

Figure 4. Equivalent circuit of single-phase DVR circuits

Figure 4 reveals the equivalent diagram of DVR where Vs indicates the supply voltage, $\mathrm{Zs}$ denotes the line Impedance, is signifies the supply current which splits at PCC into two paths i.e., into the sensitive load as $\mathrm{i}$ and injected current to other loads ir. The voltage Vpcc is the point of common coupling voltage at PCC, $\mathrm{U}$ is represented by DVR voltage, which is considered as an ideal voltage source, RL indicates the resistance \&inductance of the coupling transformer, V signifies the measured voltage across sensitive load which can be obtained using below equation.

$$
v(t)=v_{\mathrm{pcc}}(t)+u(t)-R i(t)-L \frac{d i}{d t}
$$

\section{CONTROL OF DVR}

Equation (4) was used to calculate the DVR's Power rating. For the proposed system, the DVR's Power rating is the same as the wind generator power rating assuming under without fault condition i.e., zero fault voltage drop as shown in Figure 6. Here PDVR indicates the DVR's rated power, V1 signifies the Nominal voltage and V2 denotes the lowest voltage level under fault condition, suppose in phase angle is negligible which may lead to greater power ratings [16].

Numerous control methods were developed and researched in other studies, but, in the proposed system in phase compensation approach is used [17] with neglecting the phase angle jump, which result in a lower DVR rating than the other compensation method, Figure 4 also explains the voltage compensation method in the study of In Phase compensation technique, here Ug indicates the nominal voltage of the grid, Uwg denotes the wind generator voltage, whereas U'wg \& U'gare wind generator voltage and grid voltage after the faults.

UDVR indicates the DVR injected Voltage. When faults occur, it impacts the voltage amplitude and phase angle jump. This small variation in the phase angle jumps may results in a significant transient in the starting and ending of the disturbance due to which it is not suggested in compensation of voltage variation under fault conditions. The PLL (phase lock loop) as illustrated in Figure 5 is the synchronized DVR with the grid, the reference voltage of the DVR is represented by the "U(DVR, d-q, ref)" is evaluated by considering the difference between the "grid voltage" (Ugrid) and "reference Voltage" (Uref).

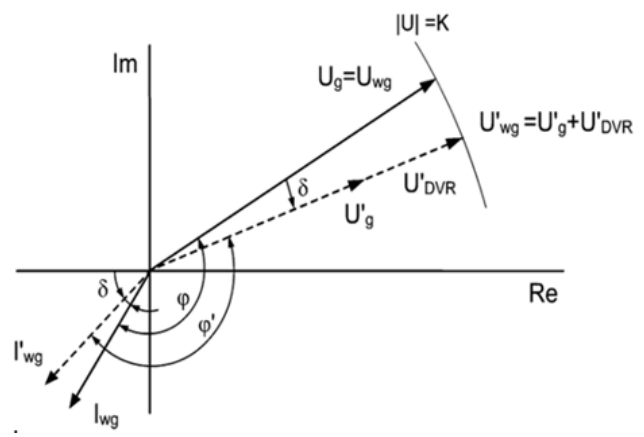

Figure 5. DVR in-phase compensation

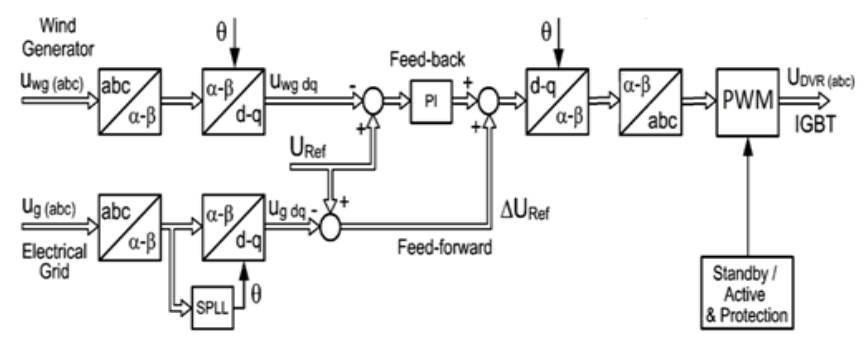

Figure 6. The control scheme of DVR

The difference between Uwg and Urefis used to calculate the DVR actual voltage U(DVR,d-q).The feed-forward compensation method and intelligent control are used in conjunction with a closed-loop control strategy to correct for the difference in voltage between the DVR voltage and the reference voltage. Results into the improvement of DVR response time which will be transformed into reference voltage for controller input to produce the Pulse for IGBT inverter. DVR scheme parameter as illustrated in Table 1 below for standard configuration of the proposed system.

Table 1. Parameter of DVR system

\begin{tabular}{cc}
\hline \multicolumn{2}{c}{ Parameters of DVR system } \\
\hline Parameter & Values \\
Rated Power & $50 \mathrm{MVA}$ \\
Transformers ratio & 1 \\
Filter Inductance & $0.14 \mathrm{mH}$ \\
Filter Capacitance & $20 \mathrm{mF}$ \\
PI controller & $\mathrm{Kp}=1, \mathrm{~K}=0.1$ \\
\hline
\end{tabular}




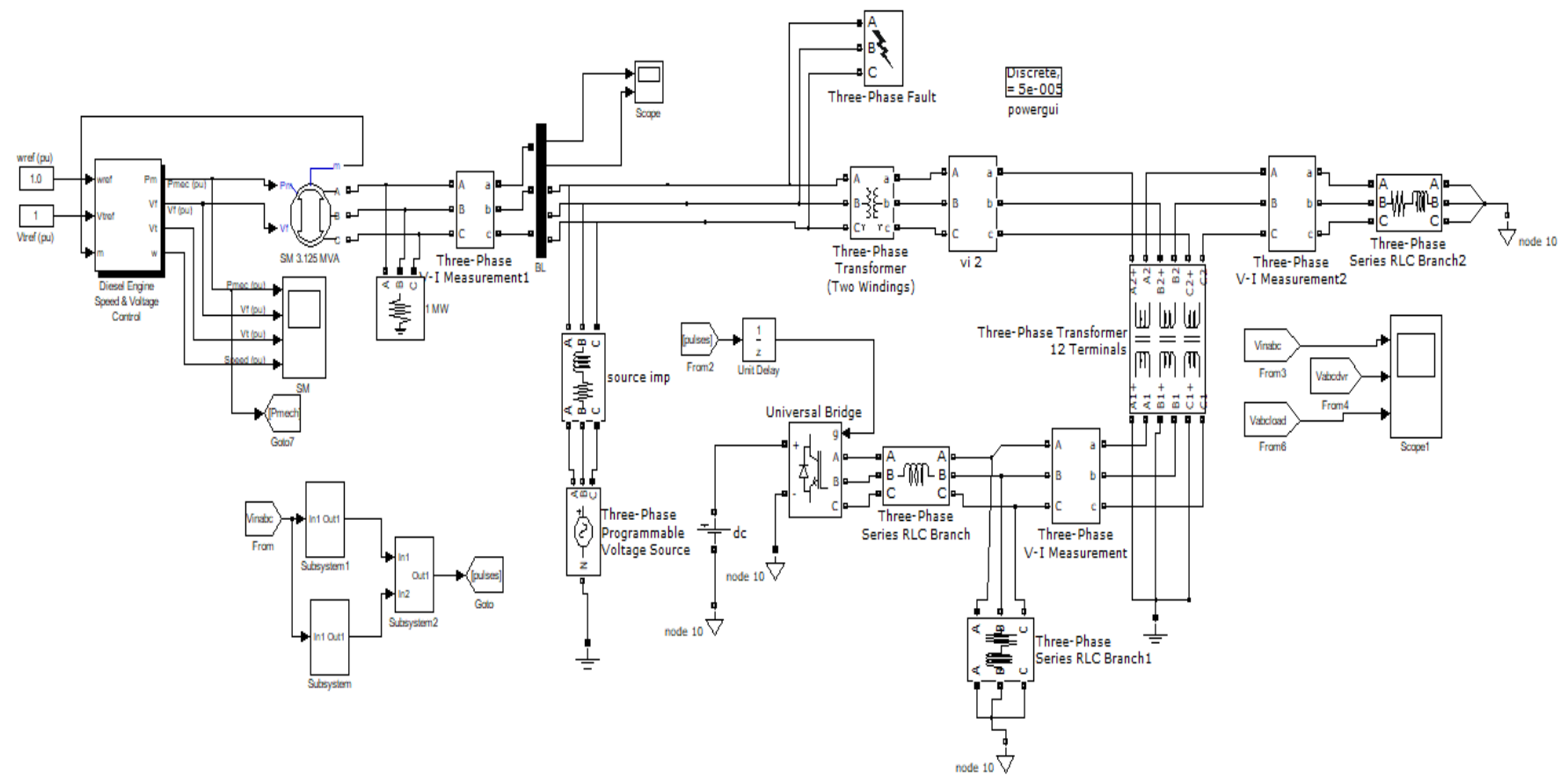

Figure 7. Simulink diagram of WTS system with DVR

\section{WIND TURBINE COMPONENTS IN SCAD/EMTDC}

The MATLAB simulation algorithm is based on the timedomain response which may be utilized for developing grid unit and multiphase power distribution systems. This simulation is used to analyze the analysis of the power system's transient behaviors with DVR. The wind turbine system model for the suggested system is given in Figure 7.

Increasing power demand from consumers made needs of wind energy supply and optimizing the wind power generation for smooth grid operation using DVR. Important aspects of the wind turbine system are given below:
$\checkmark$ Voltage imbalance
$\checkmark \quad$ Voltage profile ranges.
$\checkmark$ Voltage fluctuations
$\checkmark$ System Harmonics
$\checkmark \quad$ Reactive power Q
$\checkmark$ Grid rated Capacity
$\checkmark$ Grid Availability
$\checkmark \quad$ Frequency response range

Many wind energy usages are becoming more robust in the area of advanced power electronics. PQ improvement applications like DVR, variable speed generation, energy storage, and reactive power compensation devices may be utilized in modern wind power generation concepts $[18,19]$.

\section{WTS AND DVR SIMULATION MODEL}

In the present study, the wind turbine scheme was developed with DVR. During the occurrence of a fault in the system when connected to sensitive load is recovered and compensated with DVR. The reliability and quality of voltage may be enhanced for sensitive loads. MATLAB Simulink was used for modeling and simulation wind systems with DVR [20, 21]. The wind generator's power quality is improved using
DVR, which is a new technique suggested by the researchers. The DVR is a strong tool for safeguarding sensitive loads from damaging electrical disturbances. The DVR is capable of continuously supplying high-quality power to sensitive loads.

As a result, WTS guarantees the continuous supply of electric power for the sensitive process loads. Table 1 contains descriptions and dimensions of all the following components. The Proposed scheme for enhancing power quality of wind generators using DVR application on the distribution system connected to the loads. The DVR can be used for any external disturbances created in the distribution system and protect and loads against faults. The high-quality power may be delivered to loads on the application of DVR without any interruption. In turn WTS results in providing continuous power to loads without any interruption using DVR [22]. Following are the components that were demonstrated in Figure 7.

The wind turbine generator parameters of the proposed scheme:

Alternate source systems and WTS.

$13.8 \mathrm{kV}$ (Line to Line Voltage), $50 \mathrm{~Hz}$.

RWTS $=\mathrm{Ra}=1 \Omega$.

Three-phase start-delta load transformer.

$7.5 \mathrm{kV} / 2 \mathrm{kV}, 1 \mathrm{MVA}, 50 \mathrm{~Hz}$.

They all utilized thyristor valves with a snubber circuit comprised.

Parameter of the Load system:

$\mathrm{R}=56.25 \Omega, \mathrm{L}=0.13 \mathrm{H}$

Parameters of the Filter circuit are:

$\mathrm{R}=10 \Omega, \mathrm{L}=1.64 \mathrm{mH}, \mathrm{C}=5.66 \mu \mathrm{F}$.

The primary objective of the suggested system is to offer the dynamic performance of the wind turbine system with DVR effect analysis capabilities of the system on the basis of simulation results. The performance of DVR was illustrated in the simulated model by which we can examine the time response behavior of the system. The WTS simulation model is connected to load and DVR. 


\section{SIMULATION RESULTS \& DISCUSSIONS}

The simulations are carried out in MATLAB using temporary "Three-line-to-ground" (3LG) faults with a point of 0.2 . In discrete mode, the simulation duration is $0.4 \mathrm{sec}$ and the step time is $50 \mu \mathrm{s}$. Although the wind's speed is constantly changing, however, this fluctuation may be ignored for the purposes of transient stability study for a limited time as shown in Figures 8-13. Consequently, we have supposed a constant wind speed of $11 \mathrm{~m} / \mathrm{s}$ throughout the simulation. To clearly understand the efficiency of DVR we have injected the faults (LLL-G, LL-G, LG) on the system and verified the action of DVR in recovery the system by inject the voltage and absorbing the current for sag and swell condition, respective THD are mapped and demonstrated in waveforms. Although the wind speeds continuously varying the transient stability of wind speed is neglected over the short interval and assumed constant wind speed during simulation of Wind turbine system with DVR.

Case 1: Load Voltage without DVR

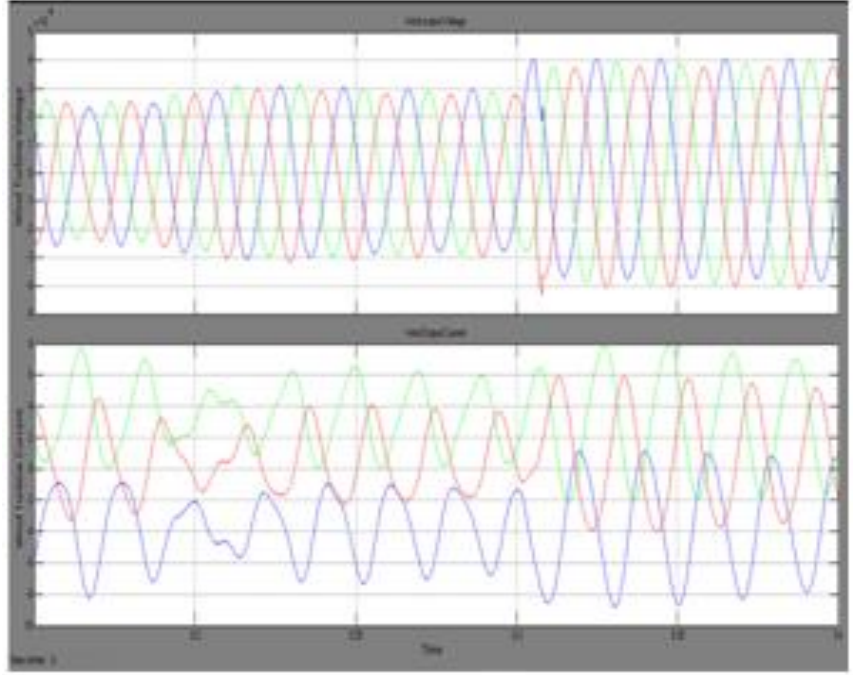

Figure 8. Wind turbine system voltage and current waveforms

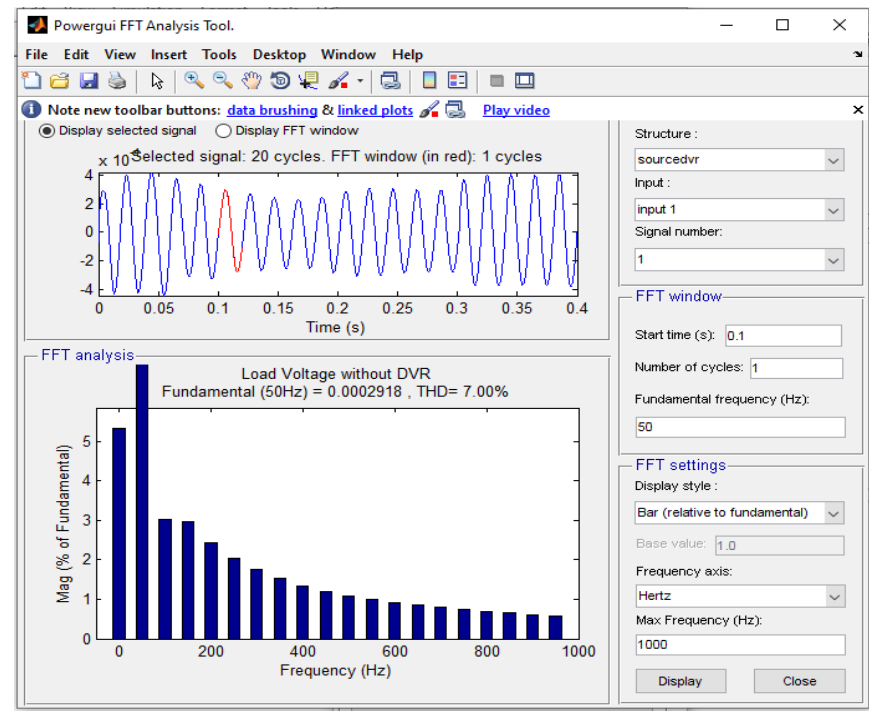

Figure 9. THD of load voltage without DVR

Case 2: DVR with Voltage Sag compensation

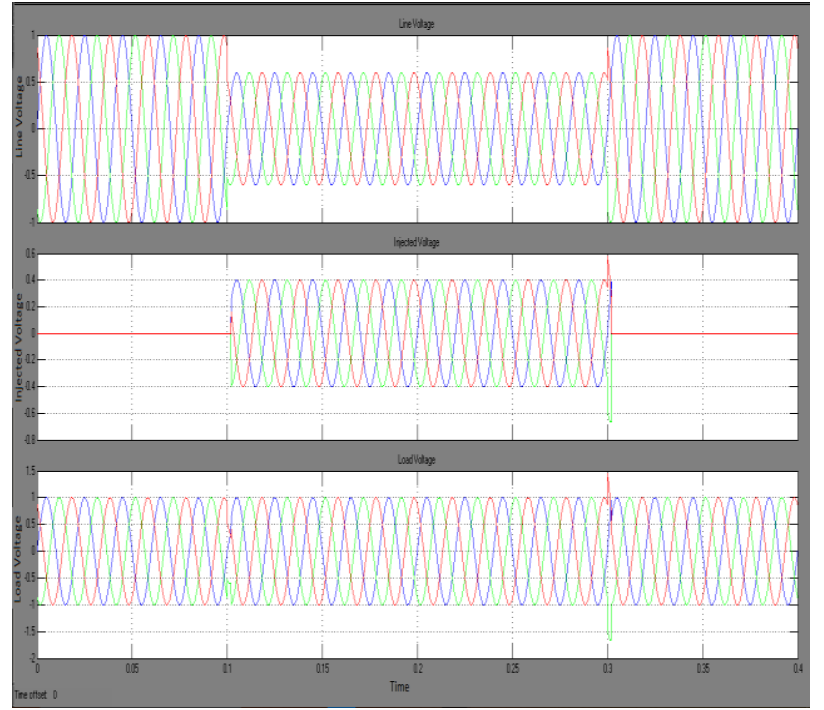

Figure 10. a) Input voltage with sag b) Injected voltage using DVR c) Load voltage

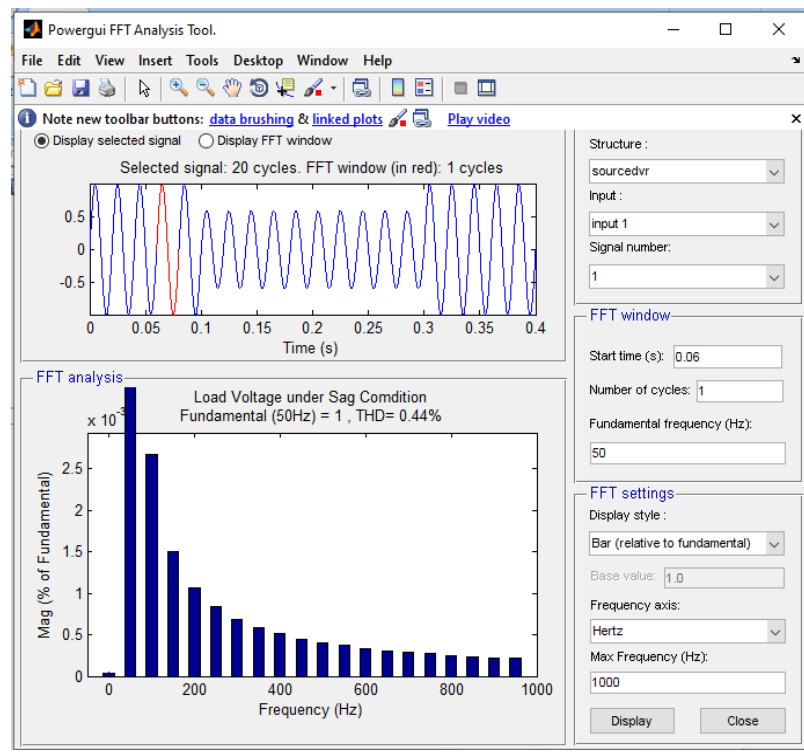

Figure 11. THD of load voltage during sag condition

Case 3: DVR with Voltage Swell compensation

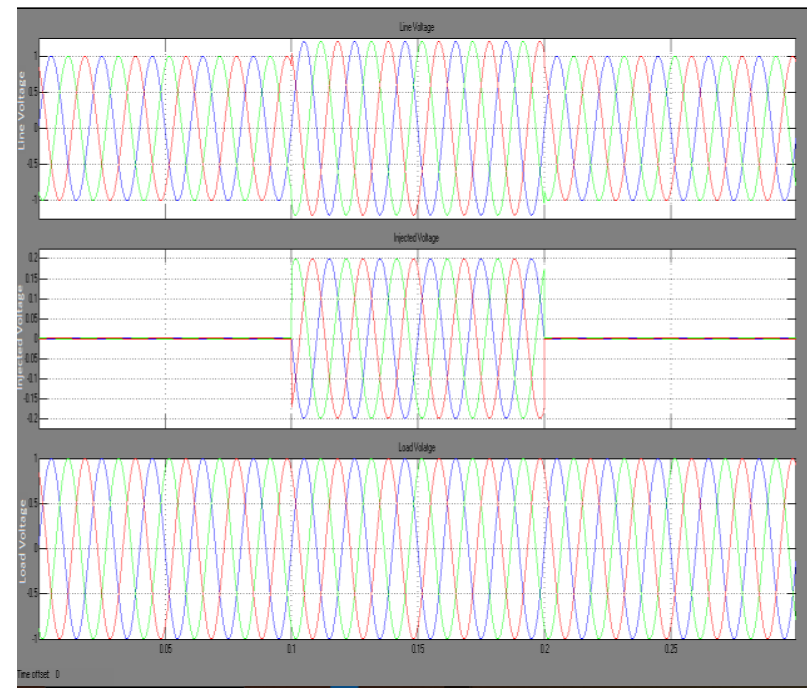

Figure 12. a) Input voltage with sag b) Injected voltage using DVR c) Load voltage 


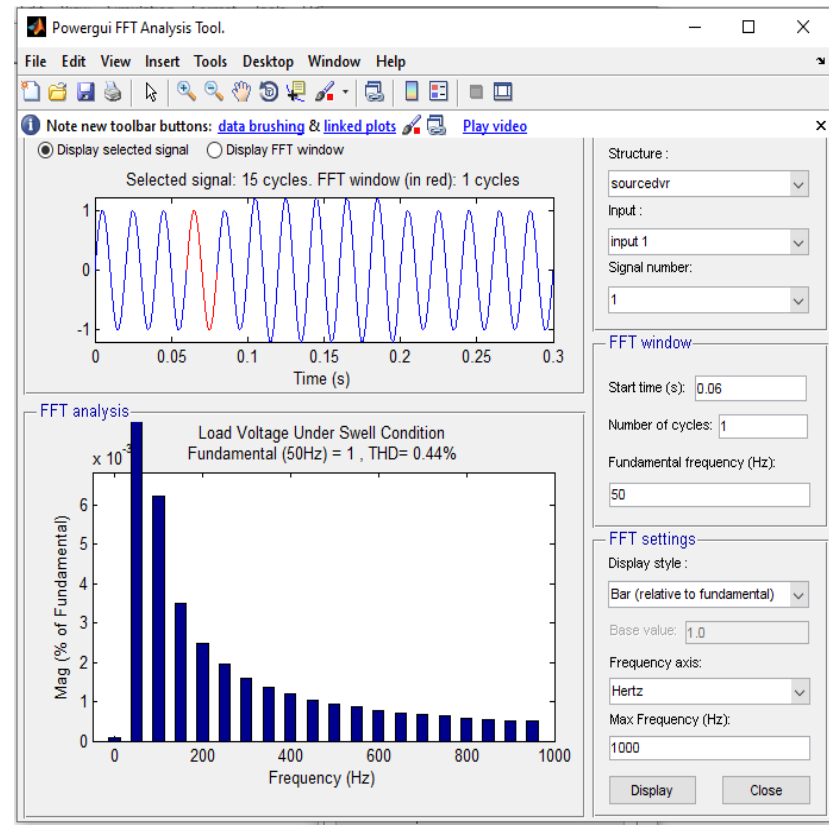

Figure 13. THD of load voltage during the swell condition

\section{CONCLUSION}

Technological improvement and increasing population in the distributed system lead to relay on renewable energy sources. The proposed system made use of a wind turbine system feeding to sensitive and other loads, creating external disturbances like sag and swell which are compensated using dynamic voltage restorer and maintain supply continuity without any interruption. In this article the wind energy capacity is considered a standard IEEE wind turbine system and the dynamic performance of the DVR is evaluated, with the result obtained it is clear that the faults recovery response time were investigated and the control algorithm is designed in this study. On the basis of result quality and reliability of wind energy are improved. The uncertainty of the wind speed causes a huge issue in the electrical outputs of the WTS but with the help of DVR which can be overcome and maintain the grid continuity without any interruption. A variable speed wind generator DFIG will be integrated into a large power system model in our future research, and the fault-ride will be analyzed by applying appropriate control techniques to enhance the concepts.

\section{REFERENCES}

[1] Gürü, M., Keskïn, A. (2016). Evaluation of biodiesel production, engine performance, and emissions. Journal of Electronic Materials, 45(8): 3882-3888. https://doi.org/10.1007/s11664-016-4573-7

[2] Firat, S. (2014). Application of efficient \& renewable energy technologies in low cost buildings and construction. Politeknik Dergisi, 17(1): 1-2.

[3] Bayindir, R., Yesilbudak, M., Cetinkaya, U. (2015). Modelling and analysing of electricity transmission infrastructure of Ankara, Turkey: A Case Study on the Critical Line Scenarios. Gazi University Journal of Science, 28(4): 587-597.

[4] Zhu, W., Cao, R.F. (2009). Improved low voltage ridethrough of wind farm using STATCOM and pitch control.
In 2009 IEEE 6th International Power Electronics and Motion Control Conference, pp. 2217-2221. https://doi.org/10.1109/IPEMC.2009.5157771

[5] Sharanya, M., Basavaraja, B., Sasikala, M. (2012). An overview of dynamic voltage restorer for voltage profile improvement. International Journal of Engineering and Advanced Technology (IJEAT).

[6] Jashfar, S., Esmaeili, S., Jahromi, M.Z., Rahmanian, M. (2013). Classification of power quality disturbances using S-transform and TT-transform based on the artificial neural network. Turkish Journal of Electrical Engineering \& Computer Sciences, 21(6): 1528-1538.

[7] Meral, M.E., Teke, A., Tumay, M. (2008). Overview of an extended custom power park. In 2008 IEEE 2nd International Power and Energy Conference, pp. 13641368. https://doi.org/10.1109/PECON.2008.4762690

[8] Jain, B., Jain, S., Nema, R.K. (2015). Control strategies of grid interfaced wind energy conversion system: An overview. Renewable and Sustainable Energy Reviews, 47: 983-996. https://doi.org/10.1016/j.rser.2015.03.063

[9] Rona, B., Güler, Ö. (2015). Power system integration of wind farms and analysis of grid code requirements. Renewable and Sustainable Energy Reviews, 49: 100107. https://doi.org/10.1016/j.rser.2015.04.085

[10] Sinha, A.K., Diwan, R., Sharma, D. (2015). Development and simulation of pi controller based pitch angle controlled DFIG system for wind turbines. International Journal of Advanced Engineering Research and Studies, 326-330.

[11] Verma, A.R., Kamani, P.L., Kapadia, R.R. (2021). A review on grid power quality improvement in wind energy system using STATCOM with BESS. In Journal of Emerging Technologies and Innovative Research, 2(1).

[12] Ye, L., Zhao, Y., Zeng, C., Zhang, C. (2017). Short-term wind power prediction based on spatial model. Renewable Energy, 101: 1067-1074. https://doi.org/10.1016/j.renene.2016.09.069

[13] Hasan, N.S., Hassan, M.Y., Abdullah, H., Rahman, H.A., Omar, W.Z.W., Rosmin, N. (2016). Improving power grid performance using parallel connected Compressed Air Energy Storage and wind turbine system. Renewable Energy, 96: 498-508. https://doi.org/10.1016/j.renene.2016.04.088

[14] Boutoubat, M., Mokrani, L., Machmoum, M. (2013). Control of a wind energy conversion system equipped by a DFIG for active power generation and power quality improvement. Renewable Energy, 50: 378-386. https://doi.org/10.1016/j.renene.2012.06.058

[15] Ajami, A., Alizadeh, R., Elmi, M. (2016). Design and control of a grid tied 6-switch converter for two independent low power wind energy resources based on PMSGs with MPPT capability. Renewable Energy, 87: 532-543. https://doi.org/10.1016/j.renene.2015.10.031

[16] Bilir, L., Imir, M., Devrim, Y., Albostan, A. (2015). Seasonal and yearly wind speed distribution and wind power density analysis based on Weibull distribution function. International Journal of Hydrogen Energy, 40(44): 15301-15310. https://doi.org/10.1016/j.ijhydene.2015.04.140

[17] Qi, W., Liu, J., Christofides, P.D. (2011). A distributed control framework for smart grid development: Energy/water system optimal operation and electric grid integration. Journal of Process Control, 21(10): 15041516. https://doi.org/10.1016/j.jprocont.2011.05.010 
[18] GWEC(Global Wind Energy Council), Global Wind 2015 report, April 2016.

[19] Kai, T., Tanaka, A. (2008). A new smooth scheme for power fluctuation using inverter of wind power generation with doubly fed induction generator. In 2008 International Conference on Electrical Machines and Systems, pp. 2390-2395.

[20] Cetinay, H., Kuipers, F.A., Guven, A.N. (2017). Optimal siting and sizing of wind farms. Renewable Energy, 101 51-58. https://doi.org/10.1016/j.renene.2016.08.008
[21] Nguyen, T.H., Lee, D.C. (2011). Improved LVRT capability and power smoothening of DFIG wind turbine systems. Journal of Power Electronics, 11(4): 568-575. https://doi.org/10.6113/JPE.2011.11.4.568

[22] Bhandare, A.M., Jadhav, K.U., Ghat, M.B. (2013). Performance of power coefficient \& power with respect to variable wind speed. In 2013 International Conference on Energy Efficient Technologies for Sustainability, pp. 466-471. https://doi.org/10.1109/ICEETS.2013.6533429 